\title{
Experimental Study on Damage Breakage Properties of Shaft Lining Concrete under Hydromechanical Coupling
}

\author{
Weipei Xue $\mathbb{D}^{1,2,3}$ Zhishu Yao $\mathbb{D}^{2},{ }^{2}$ Wei Jing $\mathbb{D}^{1,3}$ Bin Tang, ${ }^{1,2}$ Gan Kong, ${ }^{2}$ and Dezhu Xie ${ }^{1}$ \\ ${ }^{1}$ School of Civil Engineering and Architecture, Anhui University of Science and Technology, Huainan 232001, China \\ ${ }^{2}$ Research Center of Mine Underground Engineering of Ministry of Education, Anhui University of Science and Technology, \\ Huainan 232001, China \\ ${ }^{3}$ Post-Doctoral Research Station of Safety Science and Engineering, Anhui University of Science and Technology, \\ Huainan 232001, China
}

Correspondence should be addressed to Weipei Xue; xueweipei@163.com

Received 22 November 2017; Revised 24 January 2018; Accepted 4 February 2018; Published 20 March 2018

Academic Editor: Enzo Martinelli

Copyright (c) 2018 Weipei Xue et al. This is an open access article distributed under the Creative Commons Attribution License, which permits unrestricted use, distribution, and reproduction in any medium, provided the original work is properly cited.

Shaft lining concrete is exposed to a long-term coupled effect of a complex stress environment and high underground water pressure. To study the damage breakage properties under the above specific working conditions, shaft lining concrete specimens meeting the requirements of engineering application were prepared. The triaxial hydraulic coupling permeability test was conducted, and the designed osmotic pressures were $4 \mathrm{MPa}, 6 \mathrm{MPa}, 8 \mathrm{MPa}$, and $10 \mathrm{MPa}$. The results show that as osmotic pressure increases, the peak strength of shaft lining concrete decreases gradually, the surface cracks of specimen increase, and the failure mode is oblique shear failure. According to variation characteristics of permeability-strain and stress-strain curves of shaft lining concrete during loading, it is divided into three stages: compaction stage, sudden increase of permeability stage, and postpeak permeability change stage. In addition, the constitutive model of the shaft lining concrete with the influence of confining pressure and osmotic pressure was established, and the theoretical curve is in good agreement with the test curve. The damage evolution model shows that damage threshold of shaft lining concrete occurs earlier than that of ordinary concrete because of the influence of permeable water, and the damage development of the strain softening stage is particularly rapid.

\section{Introduction}

The coal mine shaft, the key element of entire mining area, has functions of lifting coal, discharging gangue, ventilating the mine, and transporting personnel and materials. With increase of mining depth, the "three high" problems of deep strata, namely, high ground pressure, high ground temperature, and high water pressure, are encountered in the process of shaft construction. Among these problems, the issue of high water pressure and large gushing water is an important aspect that degrades shaft safety. Because the shaft is subjected to the coupling of underground water pressure and other loads during the entire service period, partial function of shaft lining structure will be lost, or a water inrush accident may even occur.

When the freezing method is used for shaft sinking because of the rapid increase of freezing pressure, groundwater seepage, and freezing-thawing [1], concrete, as the main construction material of coal mine shaft, has high performance requirements (such as early strength, high strength, good impermeability, and good frost resistance); the uniaxial compressive strength of shaft lining concrete typically ranges from $60 \mathrm{MPa}$ to $100 \mathrm{MPa}$ [2].

Moreover, because the coal mine shaft is buried deep underground for the entire service period, the shaft lining concrete must withstand considerable pressure of groundwater for a long time; thus, internal and external surfaces exhibit a certain hydraulic gradient that induces high-pressure water seepage in the shaft lining concrete, resulting in hydraulic fracturing. At this point, the damage breakage properties of shaft lining concrete will inevitably change, which is notably different from that of concrete in the ground air environment.

At present, the mechanical properties of ordinary concrete under water load have been reported by many researchers. Tetsuri et al. studied the relationship between the 
concrete mechanical properties and the strain rate under saturated water and indicated that compressive strength of saturated concrete gradually increased with the increase of strain rate [3]. Cui et al. studied the damage evolution behaviour of concrete under hydrostatic pressures varying from $30 \mathrm{MPa}$ to $500 \mathrm{MPa}$ and found that the concrete suffers obvious damage if the applied hydrostatic pressure is higher than uniaxial compressive strength of concrete specimen [4]. $\mathrm{Li}$ et al. conducted strength tests under $0 \mathrm{MPa}, 2 \mathrm{MPa}$, and $4 \mathrm{MPa}$ water confining pressures for $20 \mathrm{MPa}$ concrete under two states of drying and saturation. The results show that under unsealed conditions, the triaxial strength of saturated concrete is close to its uniaxial strength. However, compared with the compressive strength of sealed specimen under the corresponding confining pressure, the strength of dry concrete decreased significantly [5]. Li and Du studied the effects of pore water on the mechanical properties of concrete by taking $15 \mathrm{MPa}$ and $20 \mathrm{MPa}$ concrete samples under different water pressures (maximum hydraulic pressure of 2.5 MPa) and observed that with increase of the pore water pressure, the compressive strength, the splitting strength, and the elastic modulus of concrete decrease gradually [6]. Alternatively, in rock hydraulic coupling research, Chen et al. studied the mechanical properties and permeability evolution of sandstone under different confining pressures and pore pressures and simulated the corresponding experiments [7]. Wang et al. used a fully automatic triaxial servo test machine with a pore water loading device to study the stress and strain law under the hydraulic coupling of an altered rock [8]. Zhao et al. applied the combination of high confining pressure and low osmotic pressure on the specimens and studied the physical and mechanical properties of the fractured limestone during the hydraulic coupling process [9]. Because shaft lining concrete has the characteristics of high strength, good impermeability, good frost resistance, dense internal structure, and other excellent characteristics, it is precisely these properties that have an important influence on the formation mechanism of the seepage field inside concrete. Therefore, compared with ordinary concrete and rock, the hydraulic coupling process of shaft lining concrete must be different; thus, the research results of ordinary concrete and rock are not suitable for shaft lining concrete. This issue has attracted the attention of the authors of this paper.

In addition, the mechanical properties of the shaft lining concrete in the water environment are rarely studied. For example, Xu et al. conducted a uniaxial compression test of high strength shaft lining concrete after water pressure action; the failure modes, compressive strength, elastic modulus, and stress-strain curves of shaft lining concrete were analysed [10]. Moreover, Xue et al. performed the three axis strength test of shaft lining concrete under the direct action of high water pressure and found that the strength of shaft lining concrete under the confining pressure of water showed the nonlinear development trend of the Bresler three parameter models [11]. Because of the high uniaxial compressive strength of the shaft lining concrete, the brittle characteristics are obvious, and the failure time is notably short. When the uniaxial test reaches its peak value, the test piece almost completely lost its bearing capacity. The triaxial test requires installation of expensive equipment and loading methods [12]. Therefore, the current research on the constitutive model of high strength shaft lining concrete is very rare. Xu obtained the curve of the softening branch of shaft lining concrete under hydraulic coupling; however, the constitutive model established only considered the single factor of confining pressure and ignored the influence of osmotic pressure, which obviously cannot explain the problem adequately [13].

Briefly, the research on the damage characteristics of shaft lining concrete under hydraulic coupling is still in its infancy; therefore, it is necessary to conduct the relevant experimental studies under the actual working environment of a coal mine shaft. A systematic investigation on the mechanical performance of shaft lining concrete at four osmotic pressures and three confining pressures was conducted in this study. The mechanical properties and failure mechanism of shaft lining concrete under different confining pressures and osmotic pressures are studied, and the two different permeability behaviours with stress strain in the hydraulic coupling process are revealed. The constitutive model of shaft lining concrete under the influence of confining pressure and osmotic pressure is established, and its damage evolution mechanism is analysed. This research results can provide a basis for the rational design and safe use of a coal mine shaft.

\section{Materials}

High-quality cement, fine aggregate, coarse aggregate, admixtures, and other raw materials are selected for shaft lining concrete pouring. Moreover, the dosage of cement, admixture, and sand in the mixture ratio can be improved. In addition, the water-cement ratio must be reduced, and the admixtures-cement ratio must be improved. Finally, Huainan Fengtai Conch Cement Plant Conch licensing P. O52.5R early strength ordinary Portland cement is selected, the performance indicators of which exceed the national standards [14]. The characteristics of the cement include a fineness modulus of 2.73 from Huaibing river sand, a measured clay content of $1.45 \%$, a maximum particle size of Mingguang basalt no greater than $19.0 \mathrm{~mm}$, and a compression index of $3.8 \%$ (prior to the test, the coarse and fine aggregate were rinsed and dried). Panda brand mineral admixture NF-F is used, which consists of composite mineral admixtures, with compensation for shrinkage, superplasticizer, and other organic and inorganic components. Among these components, the high-quality mineral admixture accounts for approximately $93.5 \%$, and the superplasticizer accounts for approximately $6.5 \%$. According to the specification for the mixture proportion design of ordinary concrete [15], when the design strength is greater than or equal to $60 \mathrm{MPa}$, the preparation strength should be calculated according to $f_{\mathrm{cu}, 0} \geq 1.15 f_{\mathrm{cu}, k}$. Finally, it is determined that the preparation strength of shaft lining concrete is $92.0 \mathrm{MPa}, f_{\mathrm{cu}, k}$ is the design strength $(\mathrm{MPa})$, and $f_{\mathrm{cu}, 0}$ is the preparation strength $(\mathrm{MPa})$. The material compositions of these concrete samples are listed in Table 1. 
TABLE 1: Mixture ratio of shaft lining concrete.

\begin{tabular}{|c|c|c|c|c|}
\hline Cement $\left(\mathrm{kg} \cdot \mathrm{m}^{-3}\right)$ & Admixtures $\left(\mathrm{kg} \cdot \mathrm{m}^{-3}\right)$ & Water $\left(\mathrm{kg} \cdot \mathrm{m}^{-3}\right)$ & Sand $\left(\mathrm{kg} \cdot \mathrm{m}^{-3}\right)$ & Gravel $\left(\mathrm{kg} \cdot \mathrm{m}^{-3}\right)$ \\
\hline 430 & 155 & 152.1 & 616.6 & 1096.3 \\
\hline
\end{tabular}

TABle 2: Physical and mechanical properties of shaft lining concrete.

\begin{tabular}{|c|c|c|c|c|c|c|c|}
\hline $\begin{array}{l}3 \mathrm{~d} \text { strength } \\
(\mathrm{MPa})\end{array}$ & $\begin{array}{c}7 \text { d strength } \\
(\mathrm{MPa})\end{array}$ & $\begin{array}{l}28 \text { d strength } \\
(\mathrm{MPa})\end{array}$ & $\begin{array}{l}\text { Slump } \\
(\mathrm{mm})\end{array}$ & $\begin{array}{c}\text { Elasticity modulus } \\
(\mathrm{MPa})\end{array}$ & $\begin{array}{c}\text { Poisson's } \\
\text { ratio }\end{array}$ & $\begin{array}{l}\text { Relative impermeability } \\
\text { coefficient }\left(\mathrm{cm} \cdot \mathrm{h}^{-1}\right)\end{array}$ & $\begin{array}{c}\text { Water } \\
\text { absorption }\end{array}$ \\
\hline 70.33 & 81.37 & 94.47 & 182 & 41237 & 0.211 & $1.14 \times 10^{-7}$ & $2.54 \%$ \\
\hline
\end{tabular}

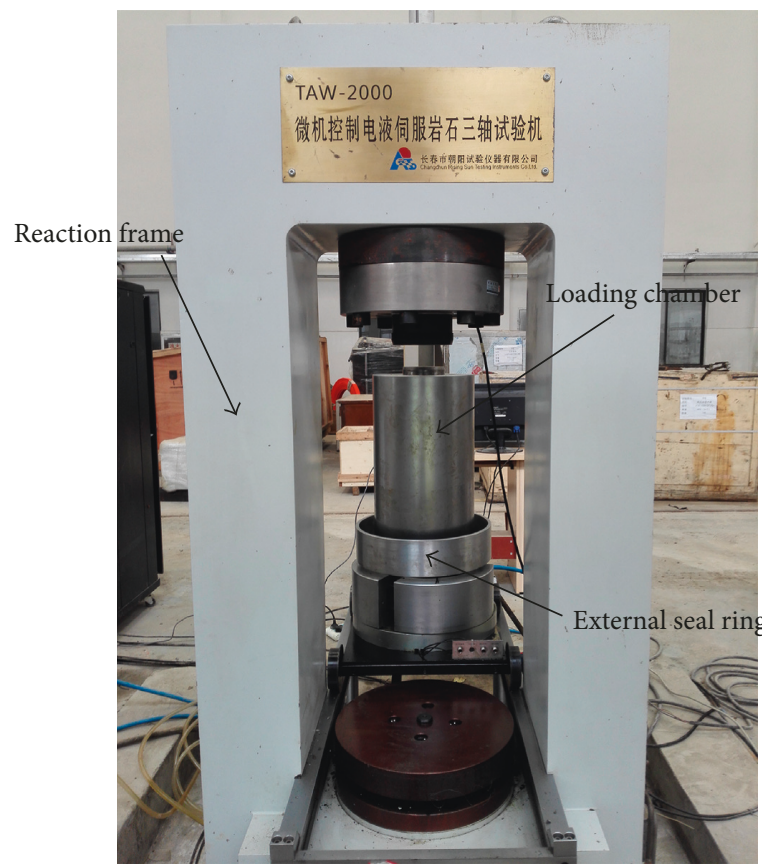

(a)

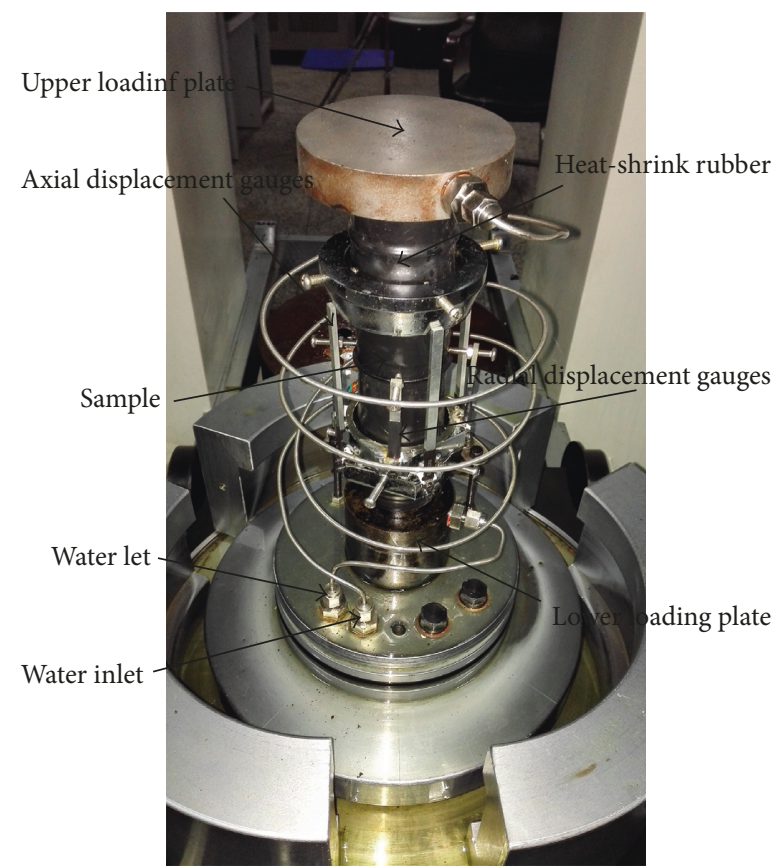

(b)

FIGURE 1: Rock three axis testing machine.

First, tests were conducted to verify whether the concrete's strength meets requirements of early strength and high strength. The results are shown in Table 2. The 3-day curing time concrete compressive strength reached more than $70 \%$ of the design strength; the 7-day curing time concrete compressive strength reached the design strength of $90 \%$ or more; the 28-day curing time concrete compressive strength has fully reached the formulation strength requirements, and its initial slump is suitable to meet the underground pumping pouring requirements. Moreover, according to standards GB/T50081-2002 [16] and GB/T50082-2009 [17], the relevant physical and mechanical properties of shaft lining concrete are tested (Table 2). Note that each physical mechanical index is obtained by averaging three samples of the same size. Therefore, frozen shaft lining concrete prepared by this test can meet the requirements of concrete strength and performance under the special construction environment and maintenance conditions of the freezing sinking method.

Finally, the $150 \mathrm{~mm} \times 150 \mathrm{~mm} \times 150 \mathrm{~mm}$ cube specimen is poured based on the mixing ratio in Table 1 after standard curing for 28 days. According to standard GB/T50266-2013
[18], a coring machine, a cutting machine, and a grinding machine are used for processing $50 \mathrm{~mm} \times 100 \mathrm{~mm}$ cylinder shaft lining concrete specimens. Each sample is cured in the indoor static pool for 45 days, to reduce the impact of age on its strength; the test is performed for saturated specimens.

\section{Experimental Campaign}

3.1. Test Apparatus. All of triaxial compression tests were conducted by using a TAW-2000 electrohydraulic servocontrolled rock mechanics testing system. The maximum confining pressure of this system is $100 \mathrm{MPa}$, and the maximum axial loading capacity of this system is $2000 \mathrm{kN}$; the machine characteristics are shown in Figure 1(a). The system is also configured with an independent closed loop capable of applying a maximum pore pressure of $60 \mathrm{MPa}$ inside the shaft lining concrete sample. This function can be used to measure absolute permeability during triaxial compression by applying pore pressure gradient between both end faces to make the fluid permeate through the shaft lining concrete sample [7]. The axial strain was measured 
TAвLE 3: Result of three axis test of shaft concrete under hydraulic coupling.

\begin{tabular}{lcccccc}
\hline $\begin{array}{l}\text { Test } \\
\text { number }\end{array}$ & $\begin{array}{c}\text { Osmotic pressure } \\
(\mathrm{MPa})\end{array}$ & $\begin{array}{c}\text { Confining pressure } \\
(\mathrm{MPa})\end{array}$ & $\begin{array}{c}\text { Peak stress } \\
(\mathrm{MPa})\end{array}$ & $\begin{array}{c}\text { Peak strain } \\
\left(\varepsilon \times 10^{-3}\right)\end{array}$ & $\begin{array}{c}\text { Initial permeability } \\
\left(10^{-18} \cdot \mathrm{m}^{2}\right)\end{array}$ & $\begin{array}{c}\text { Secant elastic modulus } \\
(\mathrm{MPa})\end{array}$ \\
\hline 1 & 4 & 7 & 121.27 & 7.59 & 3.1687 & $21.29 \times 10^{3}$ \\
2 & 6 & 7 & 106.28 & 5.96 & 4.2298 & $23.17 \times 10^{3}$ \\
3 & 6 & 9 & 128.05 & 5.98 & 2.8185 & $33.27 \times 10^{3}$ \\
4 & 8 & 9 & 124.69 & 6.80 & 6.8291 & $22.42 \times 10^{3}$ \\
5 & 8 & 11 & 136.54 & 6.99 & 4.4349 & $27.44 \times 10^{3}$ \\
6 & 10 & 11 & 127.63 & 6.21 & 6.0933 & $28.21 \times 10^{3}$ \\
\hline
\end{tabular}

simultaneously by the axial displacement gauges with a measuring capacity of $0-8 \mathrm{~mm}$ and a measurement accuracy of $\pm 0.1 \%$ at room temperature, and the radial strain was measured simultaneously by the radial displacement gauges with a measuring capacity of 0 to $4 \mathrm{~mm}$ and a measurement accuracy of $\pm 0.1 \%$ at room temperature, as shown in Figure 1(b). The reading of the axial strain was also used as a feedback signal for the external load control. In this experiment, the TAW-2000 high-precision three axis testing machine is operated by professional experimenters; the curve of the softening branch in the process of hydraulic coupling of high-strength shaft lining concrete is obtained perfectly, which provides the foundation for establishment of the constitutive model of the whole stress-strain curve. In addition, to reduce the end-friction effects on the measurements, these displacement gauges were placed at the middle height of the concrete sample, and the other two steel antifriction gaskets were placed between the end planes of the concrete sample and the upper and lower loading plates.

3.2. Test Methods. To ensure that water pressure always acts on the shaft lining concrete specimen during the test loading, a water pressure loading device must be installed [8]. When the test is conducted, the water pressure at the upper end of the specimen is always kept at the designed value, and the lower end is connected with atmosphere; thus, osmotic pressure can be easily formed. As the maximum depth of the mine shaft has reached kilometres, according to $p_{\mathrm{w}}=r_{\mathrm{w}} h$, the maximum groundwater pressure can reach $10 \mathrm{MPa}, r_{\mathrm{w}}$ is the weight of groundwater $\left(10 \mathrm{kN} / \mathrm{m}^{3}\right), h$ is the depth (m), and $p_{\mathrm{w}}$ is the groundwater pressure ( $\left.\mathrm{MPa}\right)$. Thus, the design osmotic pressures are $4 \mathrm{MPa}, 6 \mathrm{MPa}, 8 \mathrm{MPa}$, and $10 \mathrm{MPa}$ by decreasing every $2 \mathrm{MPa}$ interval. Moreover, in each set of tests, the confining pressure should be greater than osmotic pressure to ensure that heat-shrinkable plastic sleeve used in sealed samples during the test will not be broken with excessive osmotic pressure [9]; thus, the confining pressure is set at $7 \mathrm{MPa}, 9 \mathrm{MPa}$, and $11 \mathrm{MPa}$. After the test is officially started, first, $1 \mathrm{kN}$ of axial pressure is applied to ensure that the upper and lower end faces of the test specimen are in full contact with the pressure head of the test machine. Second, the confining pressure is loaded to $1.0 \mathrm{MPa}$, and $0.8 \mathrm{MPa}$ of osmotic pressure is applied. After completing the above procedures, the steady state is maintained for 30 minutes. Next, the confining pressure and water pressure are successively applied to the design value, and water saturation is kept for 15 minutes. Finally, the deformation control was conducted at $0.1 \mathrm{~mm} / \mathrm{min}$, with the confining pressure and osmotic pressure remaining unchanged. The test instrument automatically recorded the experimental data of axial stress, axial strain, circumferential strain, and water flow. It can be seen from Table 3 that two specimens were used for each of the test numbers 1 to 4 ; because of an accident during loading, for test numbers 5 and 6 , each test only used one specimen. Because the concrete specimens were all poured in the same batch, the data discreteness was small when test numbers 1 to 4 were repeated. In addition, considering the repouring concrete for supplementary testing, it is possible that the distribution of internal aggregate in the concrete specimens placed in second times is quite different from that of these test specimens. Finally, the results of this experiment are analysed.

\section{Experimental Results and Analysis}

4.1. Physical and Mechanical Properties' Change Characteristics. The experiment results of shaft lining concrete under triaxial stress-seepage coupling are shown in Table 3 and Figure 2, revealing the variation of peak stress on osmotic pressure and confining pressure. Under the same confining pressure, with the increase of osmotic pressure, the peak strength of the triaxial exhibits a downward trend; under the same osmotic pressure, the peak intensity of triaxial stress increases with increasing confining pressure. The former occurs because increasing osmotic pressure accelerates the damage process of the concrete under the same deformation conditions [19]. The latter occurs because increased confining pressure can inhibit the concrete microdefects in the germination and expansion, causing the failure stress to increase significantly. Under the same confining pressure, with the increase of seepage pressure, the peak stress of the triaxial decreases by $12.36 \%, 2.62 \%$, and $6.53 \%$; with the increase of confining pressure, the peak stress of the triaxial increases by $20.48 \%$ and $9.50 \%$. It can be seen from the stressseepage coupling test that with increase of confining pressure, the threat of osmotic pressure to peak strength gradually weakened; the confining pressure plays a leading role in the peak strength; and the osmotic pressure has a certain influence on peak strength, but the influence degree is not greater than that of the confining pressure.

The secant modulus of elasticity is calculated from $20 \%$ $40 \%$ axial stress section [20]; compared with conventional concrete mechanics test (e.g., Yan used concrete cylindrical specimens with uniaxial compressive strength of $30 \mathrm{MPa}$ for 


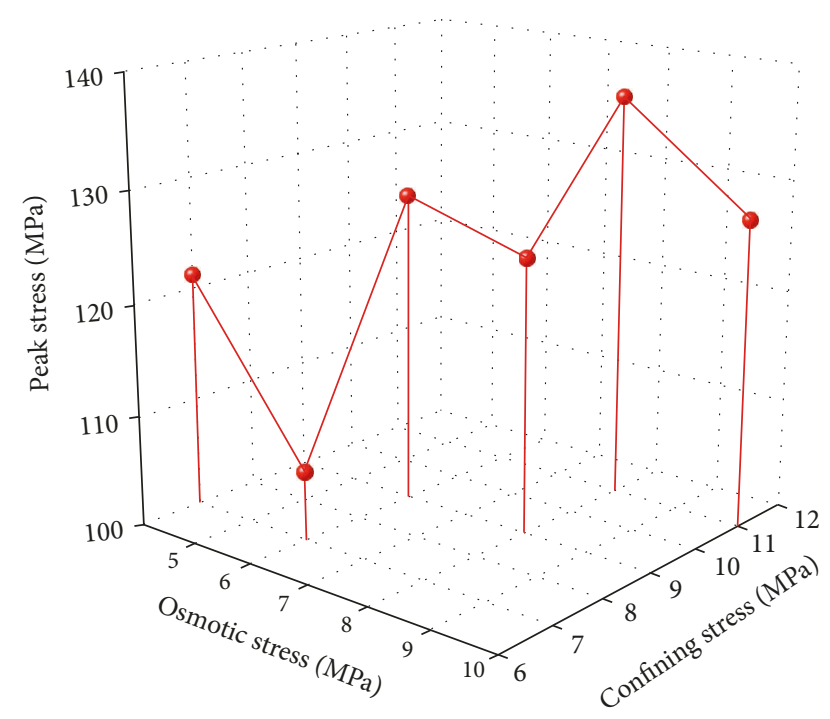

FIgURe 2: Peak stress variation curves with osmotic pressure and confining pressure.

compression tests), the average secant elastic modulus at different stress levels and strain levels was observed to be 33.75 $\mathrm{MPa}$ [21]. In addition, the higher uniaxial compressive strength of concrete corresponds to higher elastic modulus. As a result, the secant elastic modulus of shaft lining concrete is greatly reduced, showing that pressure water seepage within the concrete during stress-seepage coupling test has a more obvious effect on the damage caused by it, accelerating the deformation and failure process of the specimens [22]. This phenomenon occurs because the seepage field, stress field, and deformation field are coupled with each other; thus, under the same conditions, the degree of coupling damage increases with the increase of osmotic pressure. Therefore, the peak strength and secant elastic modulus of shaft lining concrete clearly decrease [23].

4.2. Failure Mode. The failure modes of shaft lining concrete cylinder specimens under the triaxial stress-seepage coupling are basically the same, namely, oblique shear failure, with the angle between the failure surface and the longitudinal axis of approximately $45^{\circ}$. With increase of osmotic pressure, the number of cracks on the surface of specimens increases, and the degree of damage becomes more obvious [24], as shown in Figure 3. The figure shows that pore water pressure plays a crucial role in the development of microcracks in concrete specimens, thereby aggravating penetration damage of specimens.

4.3. Relationship between Axial Stress, Strain, and Permeability. Because the permeability of prepared shaft lining concrete is greater than $10^{-19} \cdot \mathrm{m}^{2}$, according to Darcy's law, the concrete sample permeability is expressed as follows [25]:

$$
k=\frac{\mu Q L}{A \Delta p},
$$

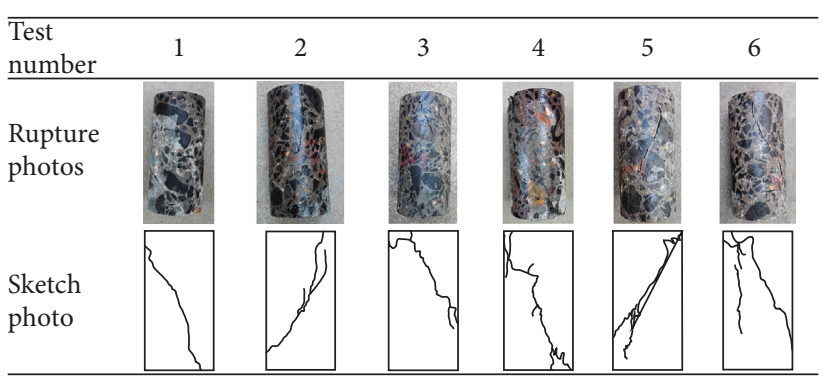

Figure 3: Specimen failure mode.

where $k$ is the shaft lining concrete test permeability $\left(\mathrm{m}^{2}\right)$, $\mu$ is the viscosity coefficient $\left(1.005 \times 10^{-3} \mathrm{~Pa} \cdot \mathrm{s}\right.$ at a room temperature of $20^{\circ} \mathrm{C}$ ), $\mathrm{A}$ is the cross-sectional area of the fluid passing through the material $\left(\mathrm{m}^{2}\right), \Delta p$ is the pore pressure difference applied between both end planes of the shaft lining concrete sample $(\mathrm{Pa}), L$ denotes the shaft lining concrete height $(\mathrm{m})$, and $Q$ denotes the volumetric water flow rate $\left(\mathrm{m}^{3}\right)$.

The evolution relationship of concrete permeability with stress strain, which can be divided into three stages, is shown in Figure 4. Stage I is the compaction stage, in which the microcracks and micropores contained in the concrete are gradually compacted and close under the joint action of confining pressure and axial pressure. The pressure water that can infiltrate the concrete interior channel is significantly reduced, thus reducing the water flow; the permeability decreases with increasing strain; the stress and strain of concrete increase linearly, and the proportion of peak value of this process depends mainly on the number of original microcracks micropores in the specimen. Stage II is the stage of surge in permeability: as axial stress continues to increase, microcracks in the concrete begin to grow and become nucleated gradually, accompanied by the initiation and coalescence of the new fractures, and the water flow begins to increase suddenly. At this stage, the permeability reaches maximum value, and the sudden increase point of permeability is often near the peak stress. However, the concrete specimen does not lose its bearing capacity. Moreover, the concrete specimen is in plastic deformation state, and the stress-strain relationship is nonlinear growth under the axial pressure continues loading. Phase III is the postpeak permeability change phase, in which the change of permeability depends mainly on microstructure of specimen and confining pressure. With the increase of deformation, the stress decreases gradually, and the mechanical behaviour shows instability [26].

Moreover, Figure 4 indicates that the change tendency of permeability-strain curve and stress-strain curve under different confining pressures and osmotic pressures can be observed in different forms. This finding indicates that there are a variety of mesomechanisms in the deformation process, and these mechanisms can be roughly divided into the following two types:

(1) Permeability increased during the first short load; immediately thereafter, the permeability begins to decrease as the axial strain increases, with the 


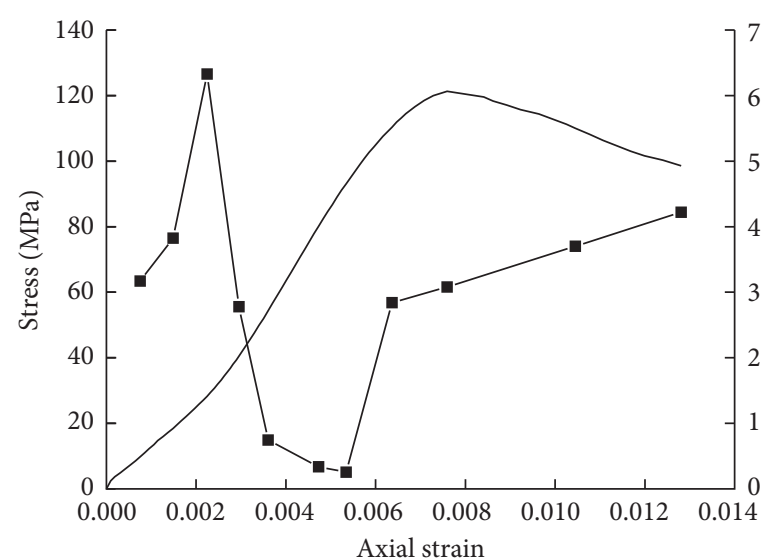

- Stress-strain curve

-₫- Permeability-strain curve

(a)

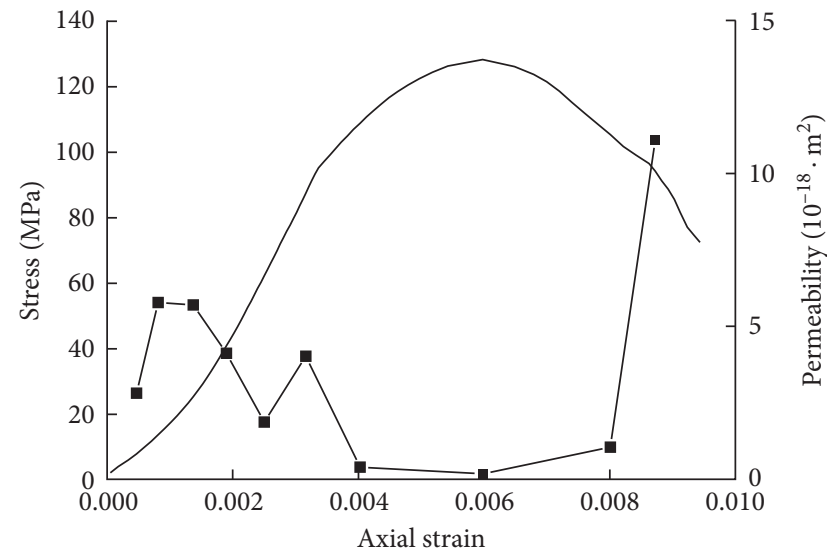

- Stress-strain curve

- - Permeability-strain curve

(c)

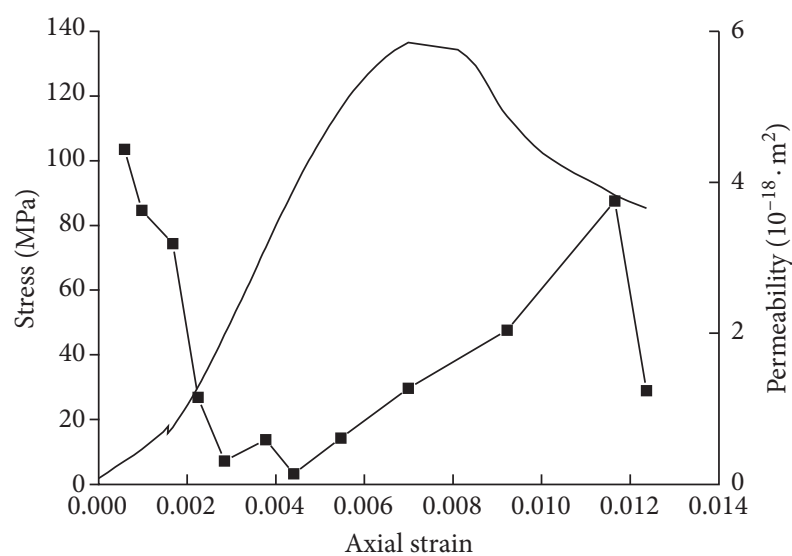

_- Stress-strain curve

- Permeability-strain curve

(e)

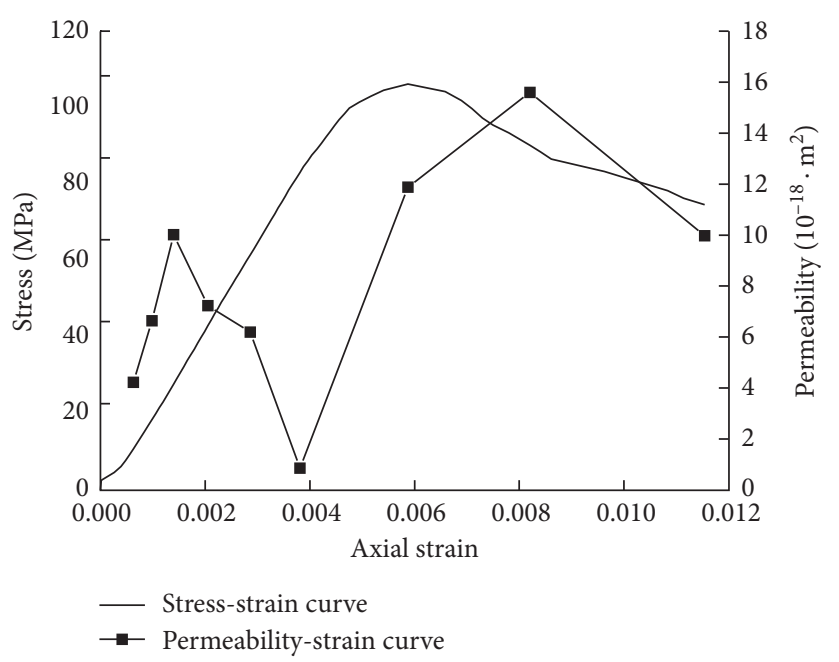

(b)

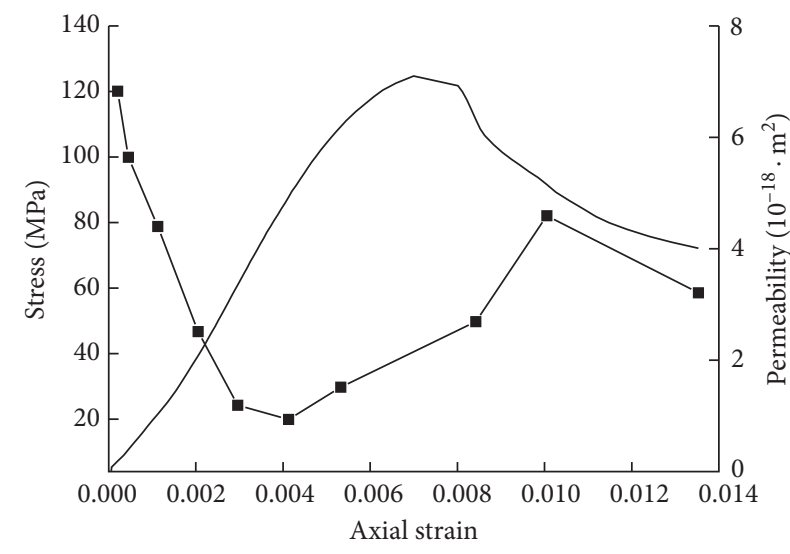

_- Stress-strain curve

- - Permeability-strain curve

(d)

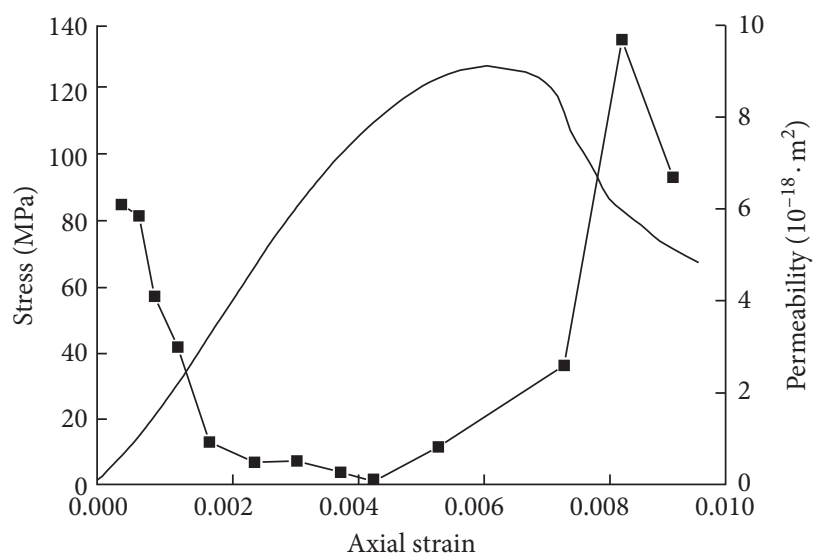

- Stress-strain curve

- - Permeability-strain curve

(f)

FIGURE 4: Stress and permeability versus axial strain of shaft lining concrete under hydromechanical coupling: (a) test number 1, (b) test number 2, (c) test number 3, (d) test number 4, (e) test number 5, and (f) test number 6. 
permeability reaching a minimum before the yield point is reached. Afterwards, the permeability increases with the increase of axial strain, and the permeability does not reach the maximum at the peak stress point, showing that the crack opening at the peak of stress does not reach the maximum, as shown in Figures 4(a)-4(c).

(2) At the beginning stage of loading, the permeability decreased with the increase of axial strain and the permeability reaches its lowest point before the yield point. Since then, along with continued increases of axial strain, the permeability increased and then it experienced a rapidly increase during the strain softening stage. Finally, the permeability decreased as the axial strain increased, as shown in Figures $4(\mathrm{~d})-4(\mathrm{f})$.

The main difference between these two permeability behaviours is the different permeability changes during the initial loading. There is a minimum threshold for the confining pressure under which osmotic pressure becomes relevant. When the confining pressure is $9 \mathrm{MPa}$ and the osmotic pressure is $6 \mathrm{MPa}$, at the initial stage of loading, some of the microcracks and micropores are not pressed, and pore water is still able to enter the specimen. However, with the continuous increase of the axial load, the microcracks and micropores in the specimen are tightly closed, and the permeability decreases. With the confining pressure of $9 \mathrm{MPa}$ and the osmotic pressure of $8 \mathrm{MPa}$, as the osmotic pressure is uniformly acting on the upper end of the specimen, consistent with the axial load applied direction, the increase of osmotic pressure is similar to the increase of axial load, and the axial load is quickly applied to the specimen. Therefore, the microcracks and micropores are compacted in the early stage of the specimen. Moreover, with the increase of confining pressure, the initial microcracks and micropores of the specimen become more compact.

\section{Theoretical Models}

The constitutive model is one of the basic frontier topics in mechanics research. The correct and practical constitutive model can well reflect and reveal the physical and mechanical properties of materials, providing an impetus for people to further understand and reasonably describe the mechanical behaviour of materials and providing a scientific basis for engineering design.

Through observation of Figure 4, it can be found that the stress-strain curve of shaft lining concrete in the hydromechanical coupling test can be divided into the hardening branch and the softening branch. Combining the characteristics of the hardening branch and the softening branch, the polynomial is finally determined to fit the curve, and the whole curve is divided into three segments. Based on the principle of the least square method [27], the characteristic parameters of each curve were fitted to these test data; thus, the segmented constitutive model of shaft lining concrete under hydraulic coupling condition is obtained. One unique aspect of this model is that it can reflect the influence of confining pressure and osmotic pressure on the stress and deformation of shaft lining concrete, as shown in the following formula:

$$
\begin{aligned}
\frac{\sigma}{\sigma_{\mathrm{pk}}}= & a_{1} \frac{\varepsilon}{\varepsilon_{\mathrm{pk}}}+\left(3.07-2.04 a_{1}\right)\left(\frac{\varepsilon}{\varepsilon_{\mathrm{pk}}}\right)^{2} \\
& +\left(1.06 a_{1}-2.10\right)\left(\frac{\varepsilon}{\varepsilon_{\mathrm{pk}}}\right)^{3}, \quad 0 \leq \frac{\varepsilon}{\varepsilon_{\mathrm{pk}}}<1, \\
\frac{\sigma}{\sigma_{\mathrm{pk}}}= & 1, \quad \frac{\varepsilon}{\varepsilon_{\mathrm{pk}}}=1, \\
\frac{\sigma}{\sigma_{\mathrm{pk}}}= & a_{2} \frac{\varepsilon}{\varepsilon_{\mathrm{pk}}}+\left(1.62-1.42 a_{2}\right)\left(\frac{\varepsilon}{\varepsilon_{\mathrm{pk}}}\right)^{2} \\
& +\left(0.47 a_{2}-0.75\right)\left(\frac{\varepsilon}{\varepsilon_{\mathrm{pk}}}\right)^{3}, \quad \frac{\varepsilon}{\varepsilon_{\mathrm{pk}}}>1 .
\end{aligned}
$$

In the upper model, $\sigma$ is the stress ( $\mathrm{MPa}), \sigma_{\mathrm{pk}}$ is the peak stress $(\mathrm{MPa}), \varepsilon$ is the strain, and $\varepsilon_{\mathrm{pk}}$ is the peak strain. The values of $a_{1}$ and $a_{2}$ are related to the confining pressure; the specific expressions of these parameters are obtained after fitting the test data:

$$
\begin{aligned}
a_{1}= & -10.6348+0.5171 \sigma_{\mathrm{o}}-0.0639 \sigma_{\mathrm{o}}^{2}+0.0046 \sigma_{\mathrm{o}}^{3} \\
& +\frac{130.6951}{\sigma_{\mathrm{c}}}-\frac{439.8211}{\sigma_{\mathrm{c}}^{2}}, \\
a_{2}= & 13.5644-2.8269 \sigma_{\mathrm{o}}+0.4022 \sigma_{\mathrm{o}}^{2}-0.0151 \sigma_{\mathrm{o}}^{3} \\
& -\frac{104.1338}{\sigma_{\mathrm{c}}}+\frac{477.1652}{\sigma_{\mathrm{c}}^{2}},
\end{aligned}
$$

where $\sigma_{\mathrm{o}}$ is the osmotic pressure $(\mathrm{MPa})$ and $\sigma_{\mathrm{c}}$ is the confining pressure ( $\mathrm{MPa})$.

Assuming that the concrete material is internally damaged, its actual undisturbed equivalent resistance volume is $V_{\mathrm{m}}$, the damage area volume is $V_{\mathrm{d}}$, and the total volume is the nominal volume $V$. The damage variable $D=V_{\mathrm{d}} / V \quad(0 \leq D \leq 1)$ is introduced by $V=V_{\mathrm{m}}+V_{\mathrm{d}}$.

According to the characteristics of stress and strain curves of shaft lining concrete under hydraulic coupling, the density function of the Weibull distribution is used to simulate the stress-strain curve [28]. Because the concrete strength follows the Weibull statistical distribution, the damage parameter of concrete can also be considered to be following the Weibull statistical distribution, in particular, the two-parameter Weibull statistical distribution given as follows:

$$
D=1-\exp \left[-\left(\frac{\varepsilon}{\alpha}\right)^{\beta}\right],
$$

where $\alpha$ is the scale parameter, $\alpha>0$, and $\beta$ is the shape parameter, $\beta>0$. 


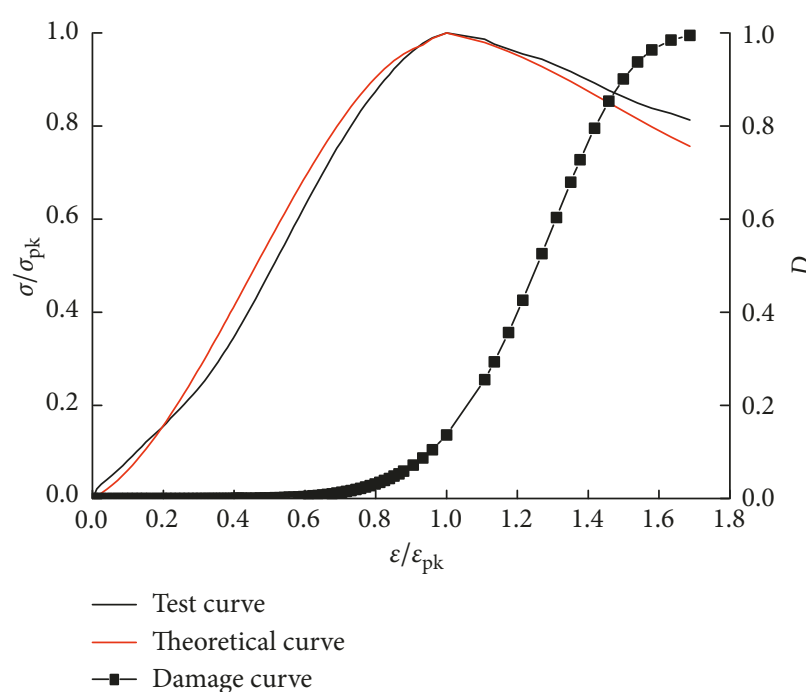

(a)

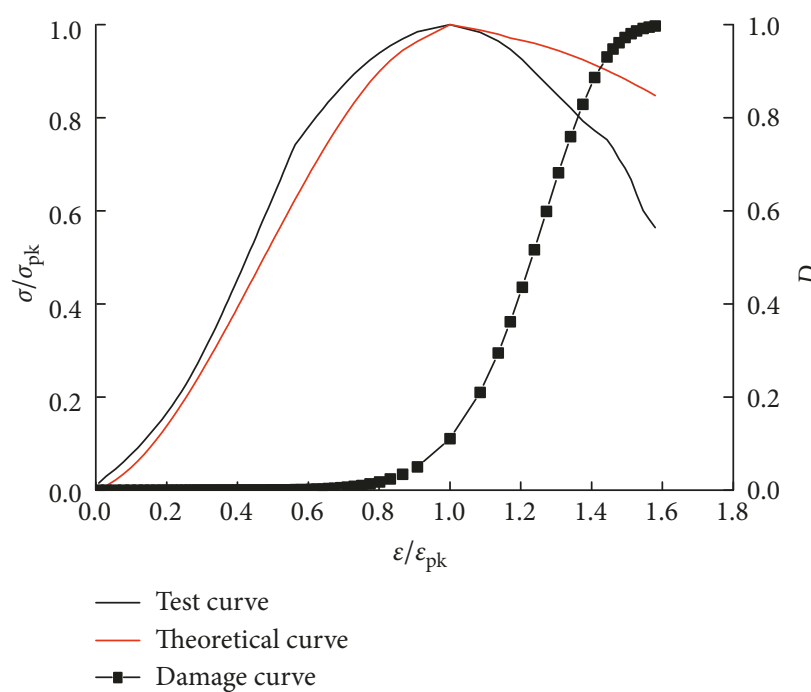

(c)

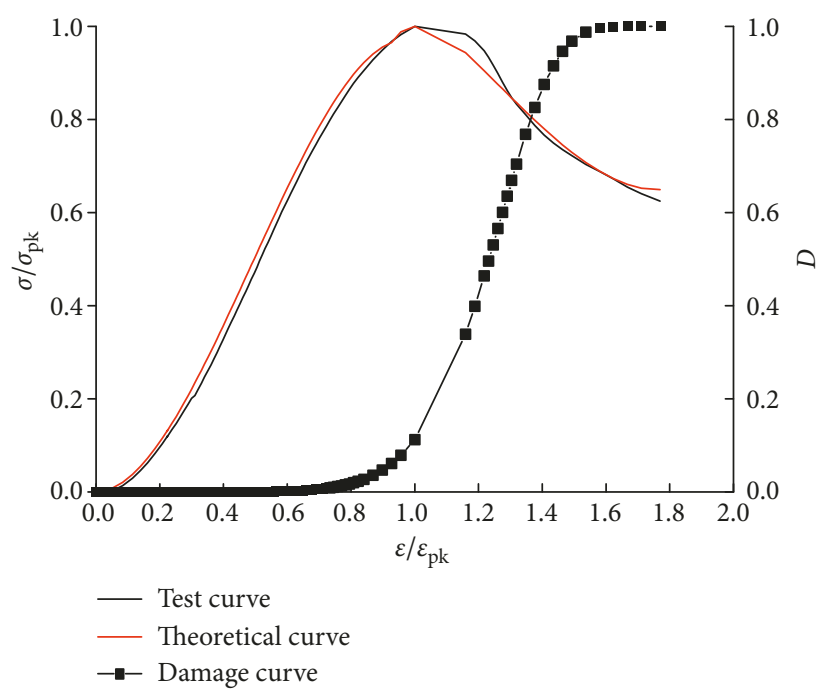

(e)

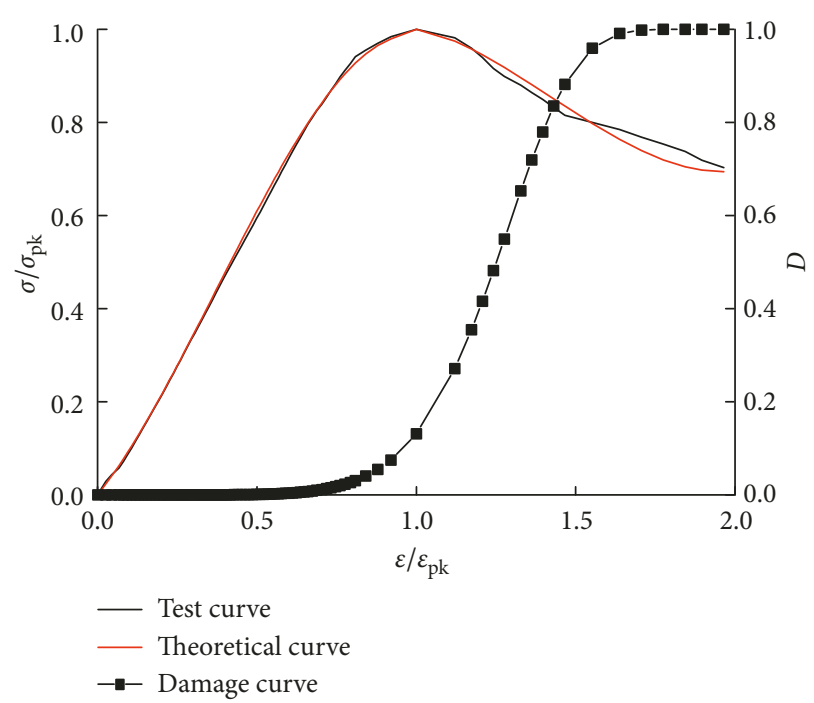

(b)

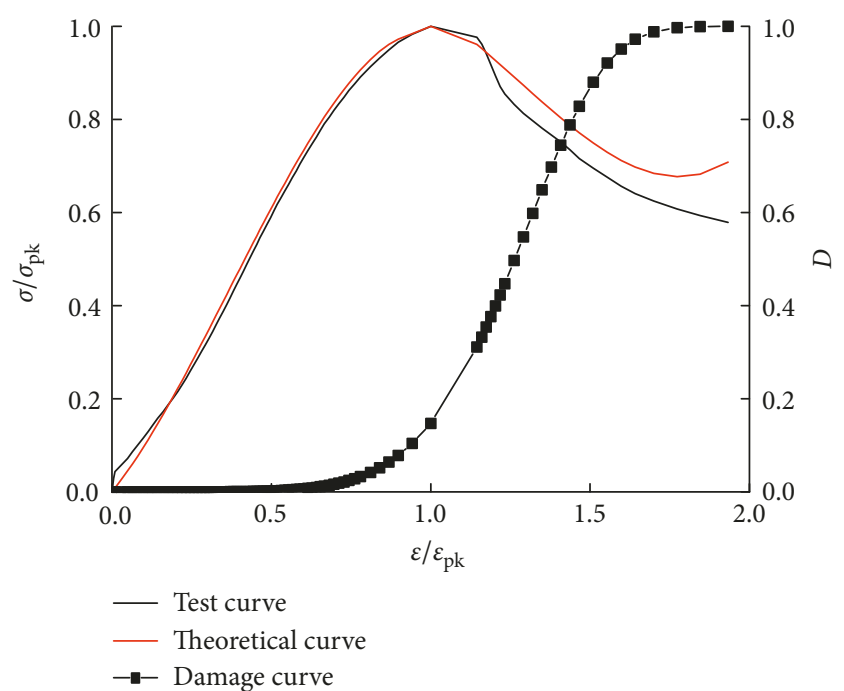

(d)

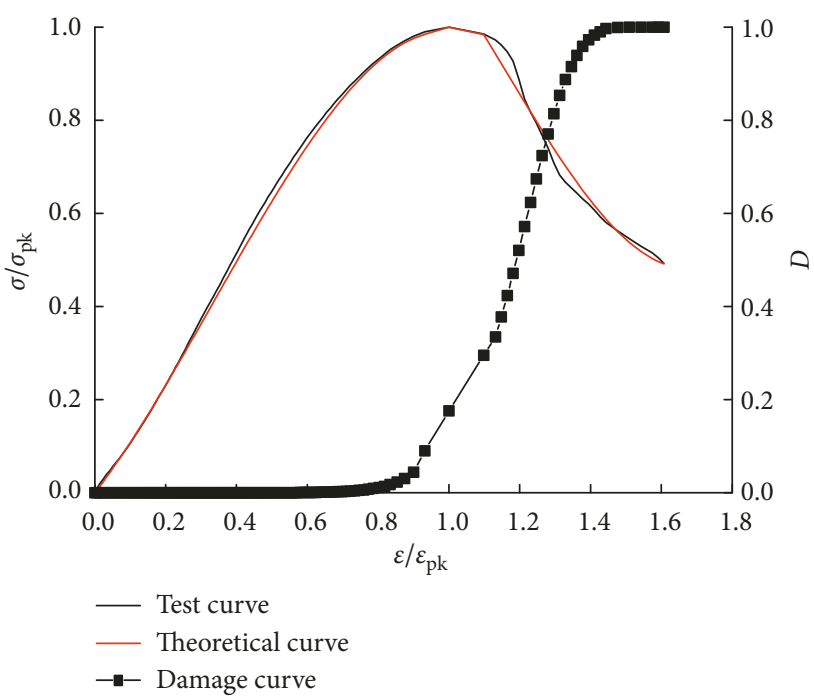

(f)

Figure 5: Curves of the damage variable and comparison of the theoretical curve with the test curves: (a) test number 1, (b) test number 2, (c) test number 3, (d) test number 4, (e) test number 5, and (f) test number 6 . 
According to the characteristics of the stress and strain curves of shaft lining concrete under hydraulic coupling, two unknown parameters $\alpha$ and $\beta$ are determined by the geometric boundary conditions.

$$
\begin{aligned}
& \alpha=\frac{\varepsilon_{\mathrm{pk}}}{(1 / \beta)^{1 / \beta}}, \\
& \beta=\frac{1}{\ln \left(E_{0} \varepsilon_{\mathrm{pk}} / \sigma_{\mathrm{pk}}\right)},
\end{aligned}
$$

where $E_{0}$ is the initial elastic modulus $(\mathrm{MPa})$.

The final expression of the damage evolution equation is as follows:

$$
D=1-\exp \left[-\frac{1}{\beta}\left(\frac{\varepsilon}{\varepsilon_{\mathrm{pk}}}\right)^{\beta}\right] .
$$

The damage factor is related to the peak stress, peak strain, initial elastic modulus, and strain of the material according to (6).

Figure 5 reveals that the fitted curves of the theoretical constitutive model obtained in this paper are highly consistent with the experimental curves and have certain reference value for engineering analysis and design. In addition, compared with ordinary concrete, the damage limit of shaft lining concrete is reached earlier under hydraulic coupling action. The initial damage of shaft lining concrete occurs near the peak point, and then damage increased gradually, especially after the peak stage.

\section{Conclusions}

In this study, laboratory tests and a theoretical analysis method were adopted to evaluate the damage breakage properties of shaft lining concrete under hydromechanical coupling. Based on the results, the primary conclusions are as follows:

(1) The early strength, high strength, low hydration heat, good frost resistance, and good impermeability of shaft lining concrete were successfully prepared, and the damage breakage properties of the concrete under hydraulic coupling were studied. With the change of confining pressure and osmotic pressure, the variation law of peak strength of shaft lining concrete was clarified and the deformation and failure characteristics of specimens were revealed.

(2) According to the seepage characteristics and stressstrain characteristics of the hydraulic coupling process of shaft lining concrete, the whole loading process is divided into three stages, namely, compaction stage, sudden increase of permeability stage, and postpeak permeability change stage. In addition, according to different mesomechanisms, the relationship between permeability and axial strain is divided into two types.

(3) Based on the analysis of test data and test curves, the segmented constitutive model that considers the influence of confining pressure and osmotic pressure in the hydraulic coupling state of shaft lining concrete was established, and the damage evolution model was established. The results show that theoretical curve is highly consistent with the test curve because of the seepage of high-pressure water in the concrete, and the damage extreme value of the shaft lining concrete is reached earlier than that of ordinary concrete.

\section{Conflicts of Interest}

The authors declare that they have no conflicts of interest.

\section{Acknowledgments}

This study was supported by the National Natural Science Foundation of China (no. 51674006), the Anhui Province University Disciplines (Professional) Top-Notch TalentFunded Projects (gxbjZD09), the Science Research Foundation for Young Teachers in Anhui University of Science and Technology (QN2017211 and QN2017222), Anhui Provincial College of Natural Science Research Key Project (KJ2018A111), and the Open Project Programme Foundation of Engineering Research Centre of Underground Mine Construction, Ministry of Education (Anhui University of Science and Technology) (nos. 2017KF03, 2017KF04, and 2017KF06).

\section{References}

[1] Y. S. Wang, Z. J. Yang, and W. H. Yang, "Viscoelastic analysis of interaction between freezing wall and outer shaft wall in freeze sinking," Procedia Earth and Planetary Science, vol. 1, no. 1, pp. 612-620, 2009.

[2] Z. S. Yao, H. Chang, and C. X. Rong, "Research on stress and strength of high strength reinforced concrete drilling shaft lining in thick top soils," Journal of China University of Mining and Technology, vol. 17, no. 3, pp. 432-435, 2007.

[3] K. Tetsuri and F. Chikako, "Mechanical properties of saturated concrete depending on the strain rate," Procedia Engineering, vol. 95, pp. 442-453, 2015.

[4] J. Cui, H. Hao, Y. Shi, X. Li, and K. Du, "Experimental study of concrete damage under high hydrostatic pressure," $\mathrm{Ce}$ ment and Concrete Research, vol. 100, no. 1, pp. 140-152, 2017.

[5] Q. B. Li, Z. F. S. Chen, M. Y. Sun, and P. Y. Lu, "Effect of water loading on strength of concrete," Shuili Xuebao, vol. 38, no. 7, pp. 786-791, 2007.

[6] Z. L. Li and S. L. Du, "Experimental study on mechanical properties of concrete due to high seepage pore water pressure," Engineering Mechanics, vol. 28, no. 11, pp. 72-77, 2011.

[7] X. Chen, J. Yu, H. Li, and S. Y. Wang, "Experimental and numerical investigation of permeability evolution with damage of sandstone under triaxial compression," Rock Mechanics and Rock Engineering, vol. 50, no. 6, pp. 1529-1549, 2017.

[8] H. L. Wang, W. Y. Xu, and J. F. Shao, "Experimental researches on hydro-mechanical properties of altered rock under confining pressures," Rock Mechanics and Rock Engineering, vol. 47, no. 2, pp. 485-493, 2014.

[9] Y. L. Zhao, J. Z. Tang, Y. Chen et al., "Hydromechanical coupling tests for mechanical and permeability characteristics of fractured limestone in complete stress-strain process," Environmental Earth Sciences, vol. 76, no. 1, pp. 1-18, 2017. 
[10] X. F. Xu, X. C. Niu, J. Liu, H. J. Wang, and T. F. Liu, "Experimental study on properties of pore water pressure affected to high-strength concrete under compressive stress," Coal Science and Technology, vol. 45, no. 3, pp. 37-42, 2017.

[11] W. P. Xue, Z. S. Yao, J. Xu, and B. D. Li, "Real strength characteristics of shaft lining concrete under the action of high pressure water," Bulletin of the Chinese Ceramic Society, vol. 35, no. 7, pp. 2254-2263, 2016.

[12] M. L. Romero, C. Ibañez, A. Espinós, J. M. Portolés, and A. Hospitaler, "Influence of ultra-high strength concrete on circular concrete-filled dual steel columns," Structures, vol. 9, no. 1, pp. 13-20, 2017.

[13] X. F. Xu, Experimental Study on Mechanical Properties of Shaft Lining High Strength Concrete under Hydraulic Pressure, China University of Mining and Technology, Beijing, China, 2016.

[14] China Standards Publication, Common Portland Cement, GB 175-2007, Standard Press of China, Beijing, China, 2007.

[15] China Standards Publication, Specification for Mix Proportion Design of Ordinary Concrete JGJ55-2011, Standard Press of China, Beijing, China, 2011.

[16] China Standards Publication, Standard for Test Method of Mechanical Properties on Ordinary Concrete GB/T50081-2002, Standard Press of China, Beijing, China, 2002.

[17] China Standards Publication, Standard for Test Method of Long-Term Performance and Durability of Ordinary Concrete, GB/T50082-2009, Standard Press of China, Beijing, China, 2009.

[18] China Standards Publication, Standard for Test Methods of Engineering Rock Mass, GB/T50266-2013, Standard Press of China, Beijing, China, 2013.

[19] M. Oda, T. Takemura, and T. Aoki, "Damage growth and permeability change in triaxial compression tests of Inada granite," Mechanics of Materials, vol. 34, no. 6, pp. 313-331, 2002.

[20] K. Zeng, J. Xu, P. He, and C. Wang, "Experimental study on permeability of coal sample subjected to triaxial stresses," Procedia Engineering, vol. 26, no. 1, pp. 1051-1057, 2011.

[21] X. L. Yan, X. B. Li, K. K. Yan, Y. G. Fan, and Y. P. Sheng, "Determination of elastic modulus of cement concrete based on compression test," Journal of Chang'an University: Natural Science Edition, vol. 35, no. 4, pp. 1-7, 2015.

[22] S. Ghabezloo, J. Sulem, S. Guédon, and F. Martineau, "Effective stress law for the permeability of a limestone," International Journal of Rock Mechanics and Mining Sciences, vol. 46, no. 2, pp. 297-306, 2009.

[23] P. Konecny and A. Kozusnikova, "Influence of stress on the permeability of coal and sedimentary rocks of the Upper Silesian basin," International Journal of Rock Mechanics and Mining Sciences, vol. 48, no. 2, pp. 347-352, 2011.

[24] L. Meng, T. Li, J. Xu, G. Chen, H. Ma, and H. Yin, "Deformation and failure mechanism of phyllite under the effects of THM coupling and unloading," Journal of Mountain Science, vol. 9, no. 6, pp. 788-797, 2012.

[25] C. A. Davy, F. Skoczylas, J. D. Barnichon, and P. Lebon, "Permeability of macro-cracked argillite under confinement: gas and water testing," Physics and Chemistry of the Earth, Parts $A / B / C$, vol. 32, no. 8, pp. 667-680, 2007.

[26] M. D. Zoback and J. D. Byerlee, "The effect of microcrack dilatancy on the permeability of Westerly granite," Journal of Geophysical Research, vol. 80, no. 5, pp. 752-755, 1975.

[27] B. Piscesa, M. M. Attard, A. K. Samani, and S. Tangaramvong, "Plasticity constitutive model for stress-strain relationship of confined concrete," ACI Structural Journal, vol. 114, no. 2, p. 361, 2017.

[28] L. E. Zapata-Ordúz, G. Portela, and O. M. Suárez, "Weibull statistical analysis of splitting tensile strength of concretes containing class $\mathrm{F}$ fly ash, micro/nano- $\mathrm{SiO}_{2}$," Ceramics International, vol. 40, no. 5, pp. 7373-7388, 2014. 


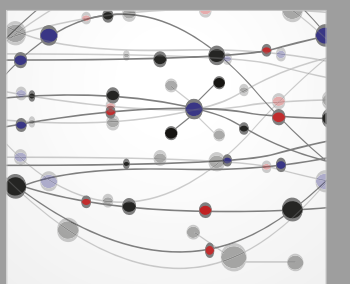

The Scientific World Journal
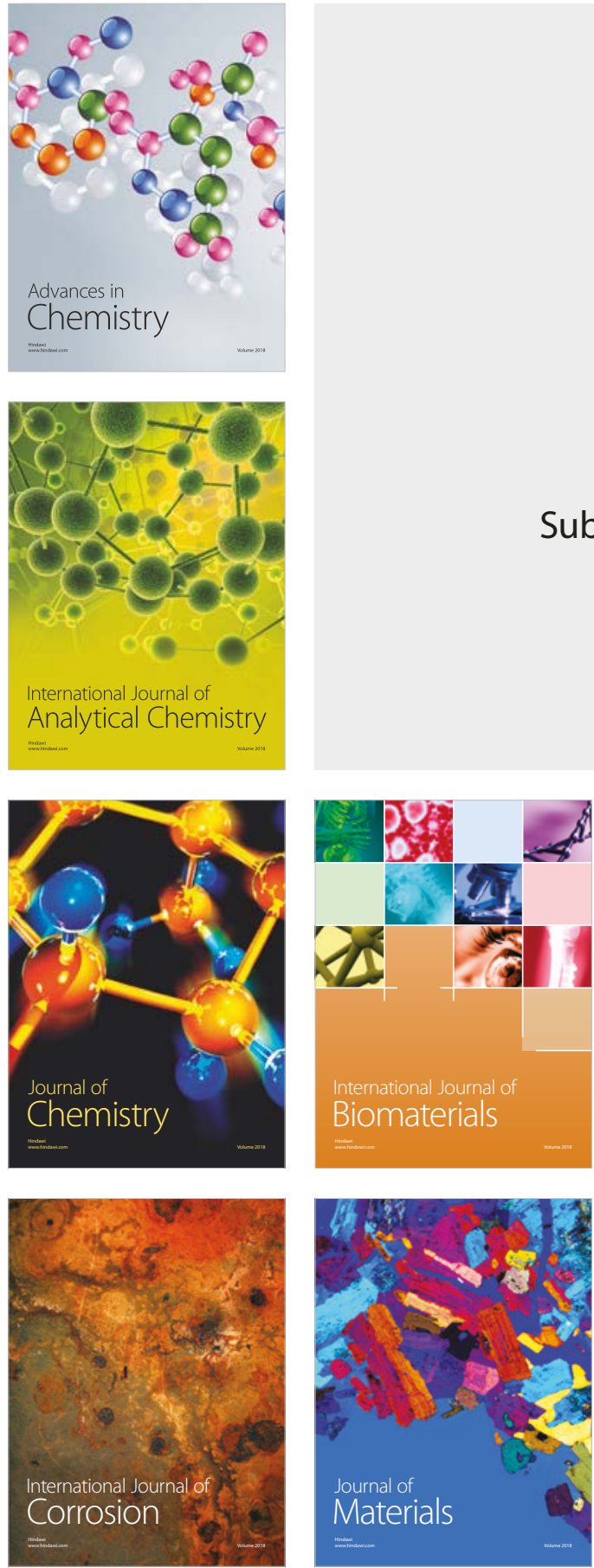

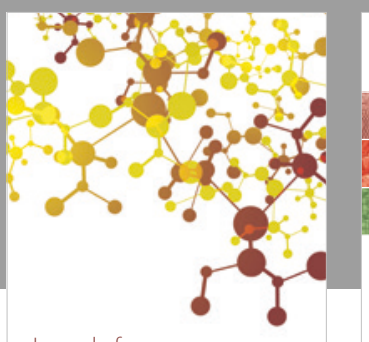

Journal of

Applied Chemistry
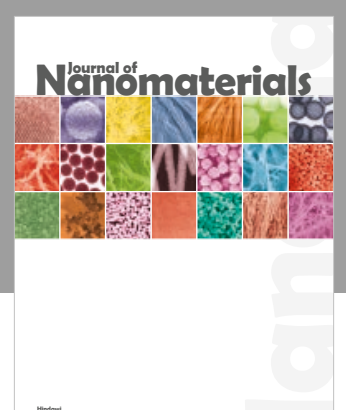

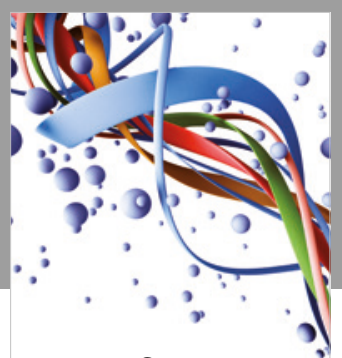

Scientifica

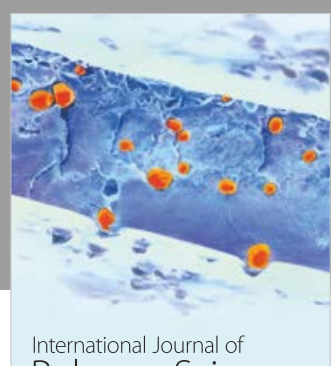

Polymer Science

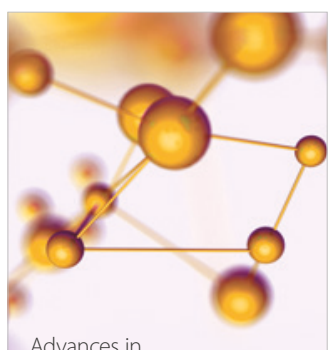

Physical Chemistry
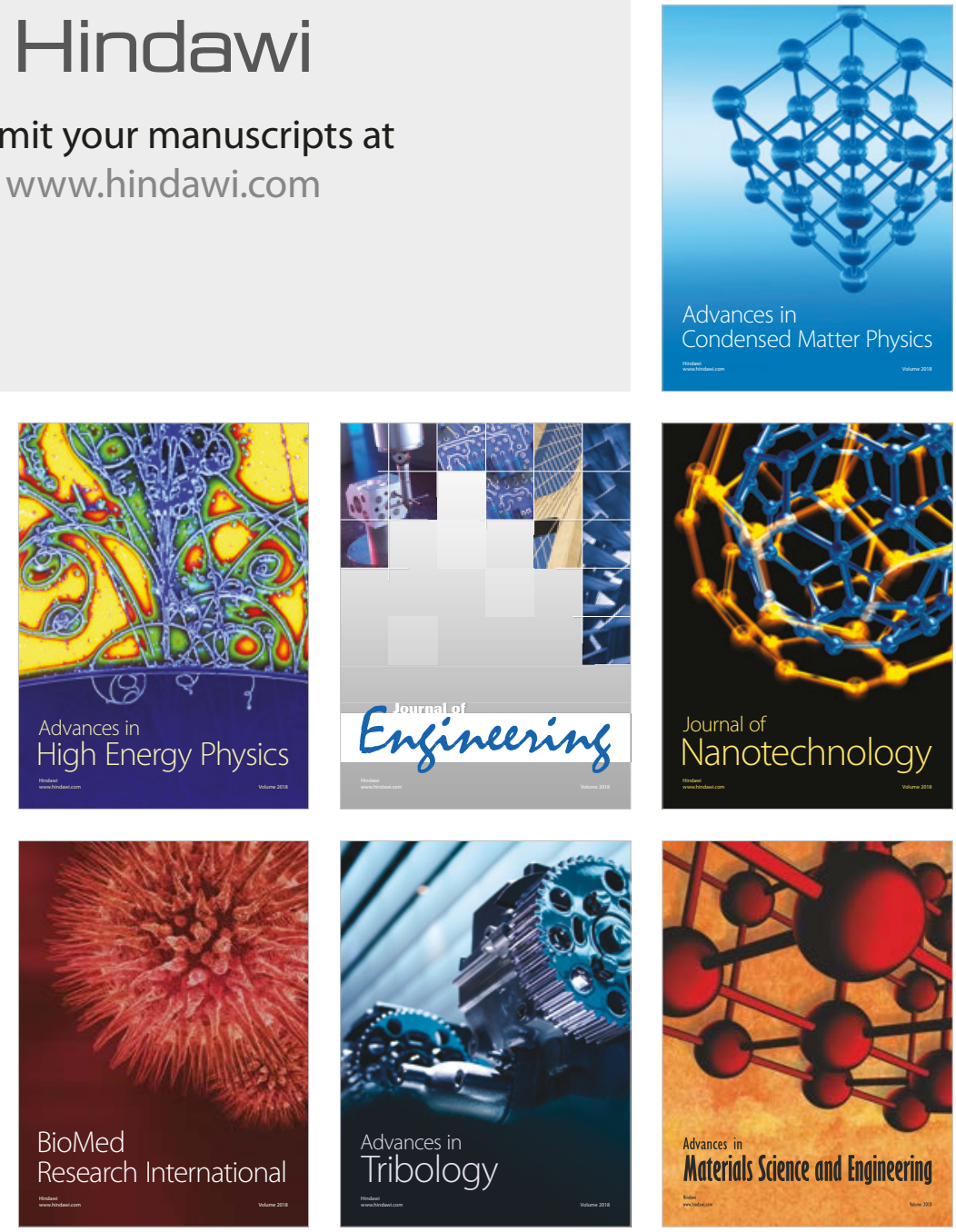